\title{
Physicochemical characterization of polymer composite cement systems
}

\author{
N. Mohamed Sutan, I. Yakub \& S. Hamdan \\ Department of Civil Engineering, Department of Chemical Engineering \\ and Sustainability and Department of Mechanical Engineering, \\ Faculty of Engineering, Univerisiti Malaysia Sarawak, Malaysia
}

\begin{abstract}
The early hydration behaviour of two different polymer composites cement systems (PCCS) that hypothetically affects efflorescence has been investigated through physicochemical characterization namely Puddle Test (PT), Standard Chemical Method (SCM), Compressive Strength Test (CS), X-ray Diffraction (XRD) and Scanning Electron Microscopy (SEM). PCCS mortar samples were prepared with water-to-cement ratio (w/c) of 0.50 . Commercially available polymer additives namely Styrene Butadiene Rubber (SBR) and Styrene Acrylic Ester (SAE) with different percentages of addition of $5 \%, 7 \%$ and $10 \%$ to cement were used. All samples were dried cured and tested at day 28. Efflorescence was accelerated by using PT. Its intensity, in terms of the amount of Calcium Carbonate $\left(\mathrm{CaCO}_{3}\right)$ precipitated on samples' surfaces, was quantified by using SEM. Results of the PCCS were then compared to the conventional cement system. Based on this study, PCCS can potentially reduce efflorescence where validation from CS, XRD analysis and SEM images showed that the evidence of the pore blocking effects of PCCS in early hydration hence can indirectly improve concrete durability and sustainability.

Keywords: polymer modified mortar, efflorescence, XRD, SEM.
\end{abstract}

\section{Introduction}

Polymer modification in cement mortar and concrete is not a new concept since the first patent for such modification was obtained in 1924. For the past 70 years or more, the active research and development of polymer-modified mortar and concrete has been performed in various countries. The application of polymer 
modified mortar and concrete is tremendously increasing in recent year especially in specialized application and increasingly accepted in construction industries $[1,2]$. Concrete polymer composites are the materials which are made by replacing a part or all of the cement binder of the conventional mortar or concrete with the polymers or in other words strengthening the cement hydrate binder with polymers. The concrete polymer composites are generally classified into the following three types by the principles of their process technology such as polymer modified cement/mortar (PMM) and polymer modified concrete (PMC), polymer mortar (PM) and polymer concrete (PC) and polymer impregnated mortar (PIM) and polymer impregnated concrete (PIC) $[1,2]$.

Polymer differs in their microstructure and interaction with cement microstructure depending on the type of polymer, method of polymerization and curing condition [2]. Polymer modified cement based materials enhance the performance of cement paste in terms of adhesion, flexural strength, abrasion resistance, shrinkage, chemical resistance, and permeability. The polymer spheres are small and can therefore block pores and capillaries and subsequently prevent water loss by reducing shrinkage. The plastic coating on the surface has a much greater resistance to the variety of chemical attack compared to the conventional mortar [1,3-5]. A similar mechanism to shrinkage cases, capillary pores are blocked and thus reducing permeability that might cause the efflorescence phenomenon.

Efflorescence, as schematically shown in Figure 1, is a deposit of crystalized calcium carbonate $\left(\mathrm{CaCO}_{3}\right)$ on the exposed concrete and cementitious materials manifesting from hazy white layers to thick white crusts [6]. This manifestation caused primarily by the leaching out of calcium hydroxide $\left(\mathrm{Ca}(\mathrm{OH})_{2}\right)$ or Portlandite, one of Portland cement hydration products, which is slightly soluble

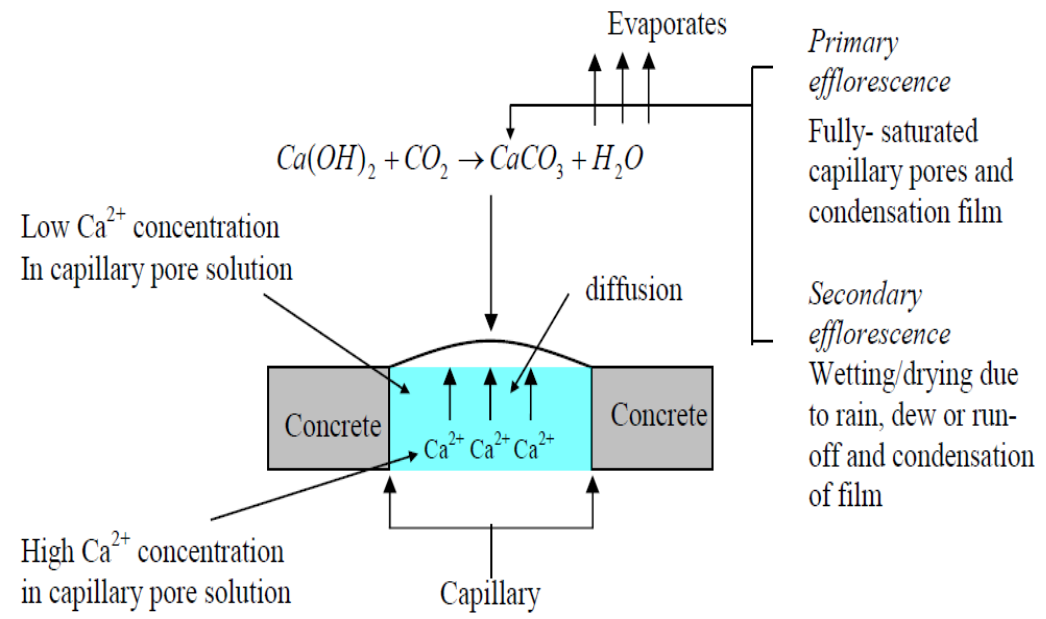

Figure 1: Schematic diagram of efflorescence from a cross-sectional view of concrete block. 
in water, migrating to the concrete surface through the capillary system of the concrete and evaporated to leave the solid $\mathrm{Ca}(\mathrm{OH})_{2}$ which then reacts with atmospheric carbon dioxide $\left(\mathrm{CO}_{2}\right)$ to form $\mathrm{CaCO}_{3}$ [7-11].

Besides the aesthetic problems mentioned, efflorescence is indirectly related to durability problem in a way that it indicates substantial $\mathrm{Ca}(\mathrm{OH})_{2}$ leaching is occurring within the concrete that can cause an increase in porosity, increase in permeability and decrease in strength, thereby increase its vulnerability to aggressive chemicals ingress $[9,10]$. To date there is no effective method to guarantee the prevention of efflorescence $[12,13]$. Hypothetically, if mortar can be made almost impermeable by blocking the pores by polymer addition, efflorescence can be mitigated by the minimization of $\mathrm{Ca}(\mathrm{OH})_{2}$ leaching. However, there are limited data available in the study of the microstructural interaction of PCCS that can possibly reduce efflorescence. Therefore the purpose of this study is to investigate the effect of PCCS on efflorescence by focusing on the characterization and morphology of PCCS in comparison to conventional mortar.

\section{Materials and methods}

\subsection{Materials}

Polymeric chemical admixtures used in this study were Styrene Butadiene Rubber (SBR) (Synthomer Grade 29Y46) and Styrene Acrylic Ester (SAE) (Revacryl Grade 477) from Synthomer UK. Ordinary Portland Cement (OPC) (ASTM Type 1 recognized by ASTM C150) manufactured by Cahaya Mata Sarawak Cement Sdn. Bhd (CMS) exceeded the quality requirements specified in the Malaysian Standard MS 52: Part 1: 1989 Specifications for Ordinary Portland Cement. The raw materials were clinker (90\%), limestone (5\%), and gypsum $(5 \%)$. The chemical and mineralogical characteristics of the OPC are given in Table 1. To study the effect of polymer addition in cement to efflorescence, $5 \%, 7 \%$ and $10 \%(\mathrm{w} / \mathrm{w})$ of liquid SBR and SAE were added to cement mortar and comparative physicochemical analysis were performed using Puddle Test (PT), Standard Chemical Method (SCM), Compressive Strength Test (CS), X-ray Diffraction (XRD) and Scanning Electron Microscope (SEM).The mix proportion was set at 1:1.67:0.5(w/c)for all samples that were casted into Universal Container $30 \mathrm{ml}, 28 \times 85 \mathrm{~mm}$ for PT,SCM,XRD and SEM and $150 \mathrm{~mm}$ X $150 \mathrm{~mm} \mathrm{X} 150 \mathrm{~mm}$ cubes for CS test. All samples were drycured in the concrete laboratory with average temperature (T) of $32^{\circ} \mathrm{C}$ and relative humidity $(\mathrm{RH})$ of $90 \%$.

Table 1: Chemical composition of OPC.

\begin{tabular}{|c|c|c|c|c|c|c|c|c|c|c|}
\hline Composition & $\mathrm{CaO}$ & $\mathrm{SiO}_{2}$ & $\mathrm{AL}_{2} \mathrm{O}_{3}$ & $\mathrm{Fe}_{2} \mathrm{O}_{3}$ & $\mathrm{SO}_{3}$ & $\mathrm{MgO}$ & $\mathrm{Na}_{2} \mathrm{O}$ & $\mathrm{K}_{2} \mathrm{O}$ & LOI & Others \\
\hline$\%$ & 63.0 & 21.79 & 5.75 & 3.25 & 2.35 & 1.97 & 0.5 & 0.28 & 1.0 & 0.11 \\
\hline
\end{tabular}




\subsection{Test methods}

\subsubsection{Efflorescence tests}

PT and SCM were performed at day 7, 14, 21 and 28. Puddle test is an accelerated efflorescence test where distilled water of $10 \mathrm{ml}$ was added on samples surfaces in the form of circular drops $[5,6]$. The water in the circle could vaporized or absorbed by the samples. On specified day, the surface of the samples was scraped to extract powder of 1 gram in weight. SCM was used to quantify the amount of $\mathrm{CaCO}_{3}$ from the extracted powder by dissolving it in a diluted hydrochloric acid solution. The dissolved salts was then placed on a filter paper and weighted before it was oven dried for 24 hours at temperature between $90^{\circ} \mathrm{C}-100^{\circ} \mathrm{C}$. Then the sample was taken out and weighted again. The weight loss indicated the amount of the dissolved efflorescence formed on the mortar samples surface.

\subsubsection{Characterization by XRD and SEM}

The fine powder samples (passing $75 \mu \mathrm{m}$ ) and polished small samples were prepared and analysed using XRD and SEM at day 28 respectively. Acetone was used to stop the hydration process of these samples. XRD analysis for all prepared samples was performed with PANalytical equipment with $\mathrm{CuK} \alpha$ radiation and $\lambda$ of $0.1546 \mathrm{~nm}$ of running $\mathrm{kV}$ and $30 \mathrm{~mA}$. The specifications were: count step: $4 \mathrm{sec} / \mathrm{step}$, step size: 0.02 degree step size and range: 50-650 $2 \Theta$ angle. SEM images for all prepared samples were captured by a Scanning Electron Microscope (JSM-6701F) supplied by JEOL Company Limited, Japan that followed the ASTM C 1723-10 (2010) code of practice.

\subsubsection{Mechanical test}

28 days' CS test was performed according to BS 1881-116 (1983) on $150 \mathrm{~mm}$ cubes samples. It was used to determine the maximum compressive load that a sample can carry per unit area. The compressive strength gave the overall picture of the quality of concrete.

\section{Results and discussions}

Figures 2 and 3 shows the percentage of $\mathrm{CaCO}_{3}$ collected from the surfaces of SAE and SBR PCCS mortar samples of $0.5 \mathrm{w} / \mathrm{c}$ ratio for 7, 14, 21 and 28 days. They also show that SAE and SBR PCCS samples exhibited more calcium carbonate $\left(\mathrm{CaCO}_{3}\right)$ formation at day 7,14 , and 21 in comparison to Control samples but lesser than Control at day 28. Figure 4 show that SAE PCCS samples exhibited the least $\mathrm{CaCO}_{3}$ formation in comparison with SBR PCCS and Control. This is in agreement with previous findings that established the $10 \%$ optimum addition of SAE $[1,2]$. Since SBR is not a reactive polymer therefore there is no interaction between polymer and cement hydration. Figure 5 of XRD patterns for SBRPCCS show more $\mathrm{Ca}(\mathrm{OH})_{2}$ than OPC, therefore minimum leaching to form efflorescence. During the hydration, hydrophilic part of the polymer was oriented towards the water phase whereas the hydrophobic part 
headed towards the air phase (pores and capillaries that were not filled with water). Upon drying which was on day 28 , as the water taken away, the hydrophobic particles coalesced together to form film and block the pores hence the later occurrence of pore blocking effect $[2,5]$. On the other hand SAE copolymer is a reactive polymer where ester linkage can form crosslink with $\mathrm{Ca}^{2+}$ ion preventing $\mathrm{Ca}(\mathrm{OH})_{2}$ from leaching [2]. This reaction has caused SAEPCC manifested the least efflorescence and the most impermeable among the samples as reflected in Figures 6, 7 and 8 with the weakest peak of $\mathrm{Ca}(\mathrm{OH})_{2}$ for $10 \%$ SAEPCCS, pore blocking SEM image of SAEPCCS and the strongest $\mathrm{CS}$ respectively.

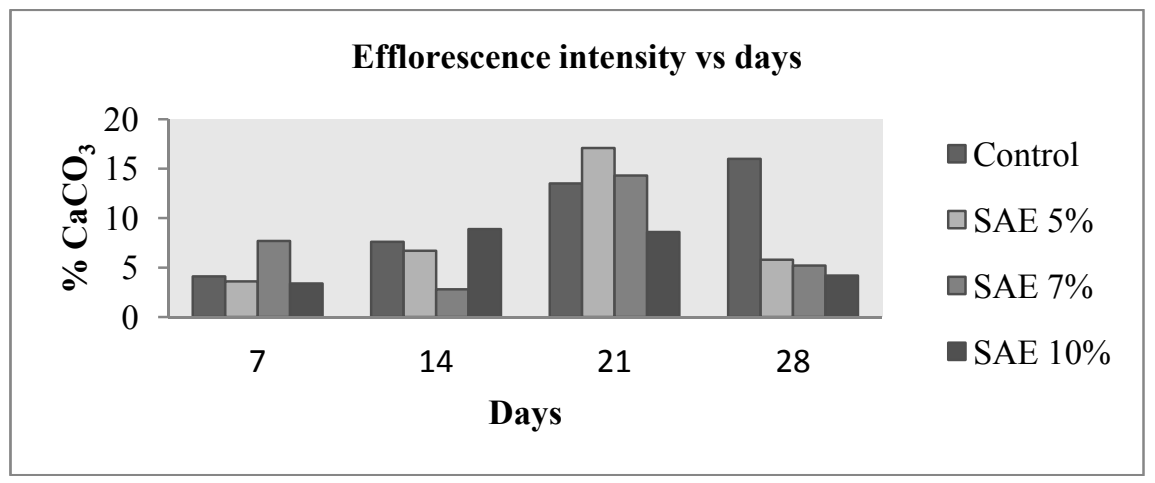

Figure 2: Comparison of percentage (\%) of $\mathrm{CaCO}_{3}$ versus days for SAEPCCS with OPC (control).

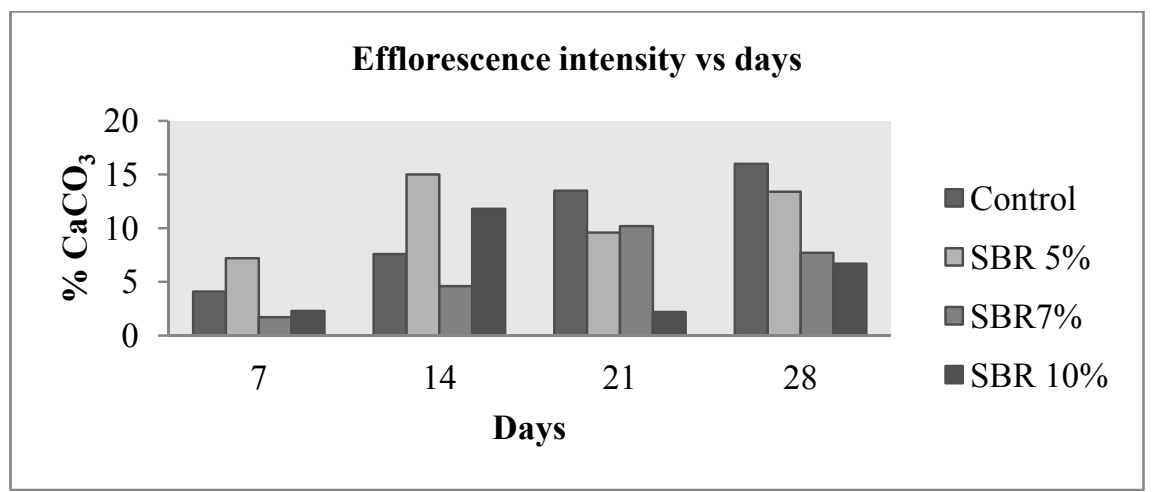

Figure 3: $\quad$ Comparison of percentag $(\%)$ of $\mathrm{CaCO}_{3}$ versus days for SBRPCCS with OPC (control). 


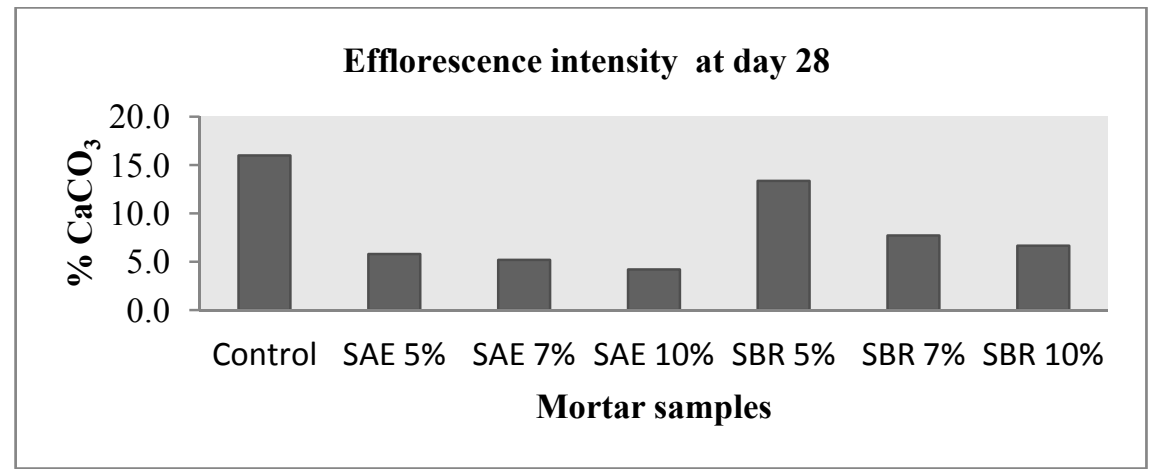

Figure 4: Comparison of percentage (\%) of $\mathrm{CaCO}_{3}$ between $\mathrm{OPC}$ (control) SBRPCCS and SAEPCCS.

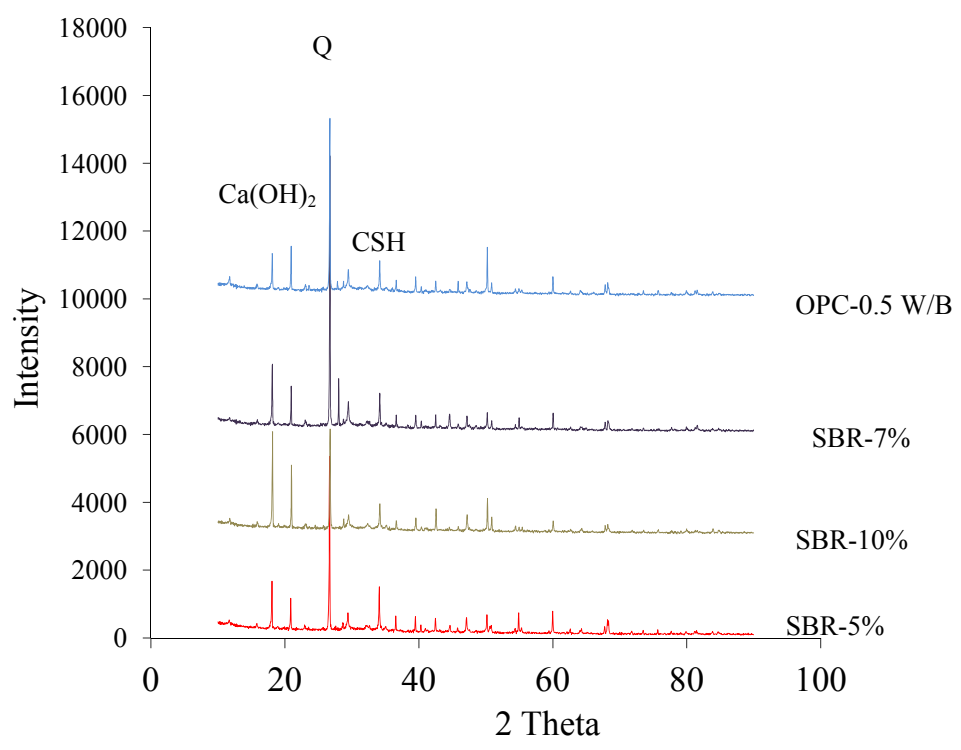

Figure 5: $\quad$ XRD pattern (CuK $\alpha$ radiation) SBRPCCS and OPC (control) at day 28 . 
High Performance and Optimum Design of Structures and Materials 109

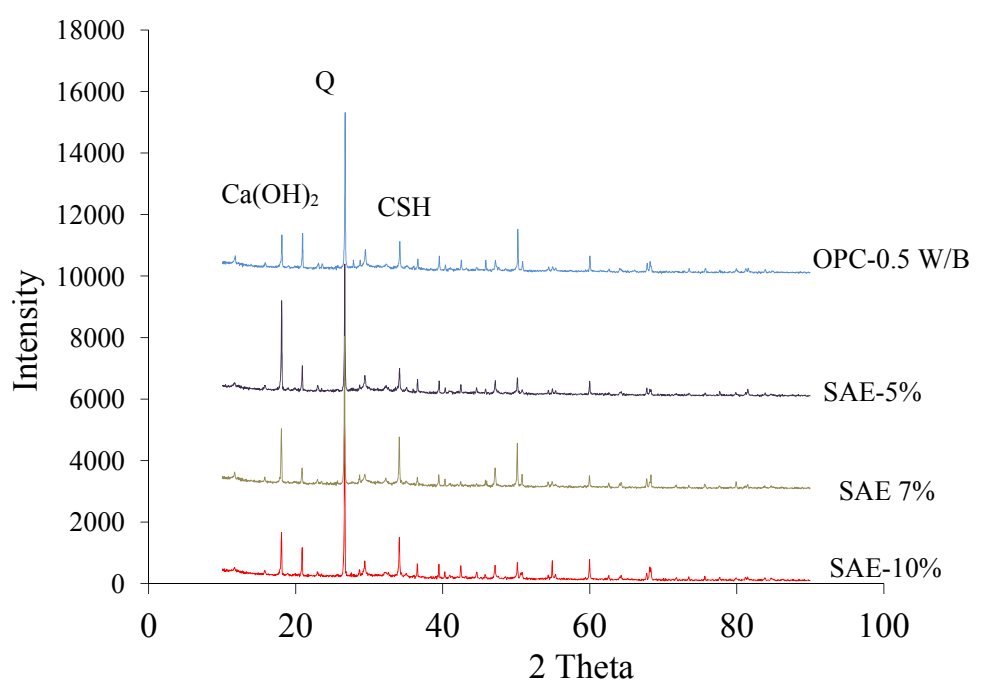

Figure 6: XRD pattern (CuK $\alpha$ radiation) SAEPCCS and OPC (control) at day 28.

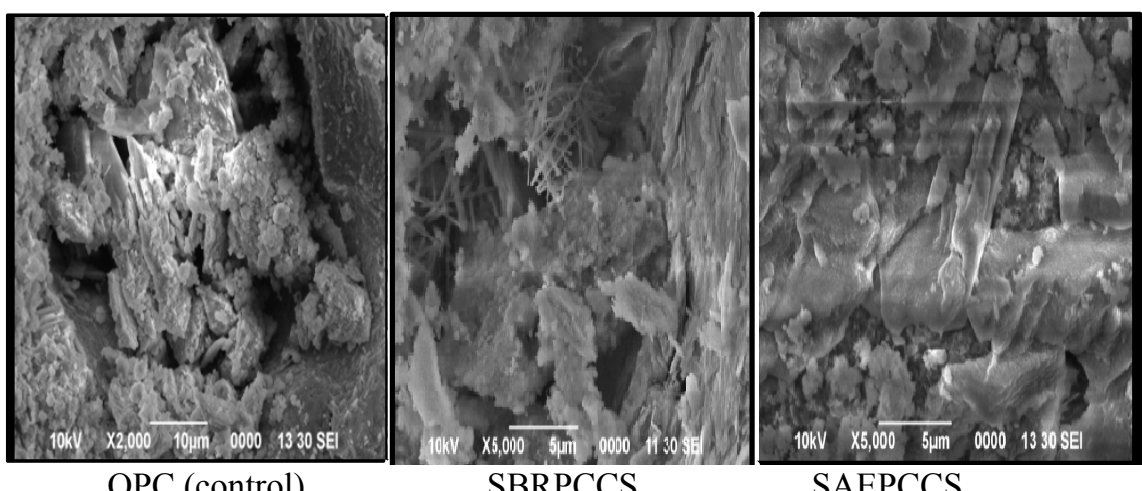

Figure 7: SEM images of OPC (control), SBRPCCS and SAEPCCS at day 28 . 


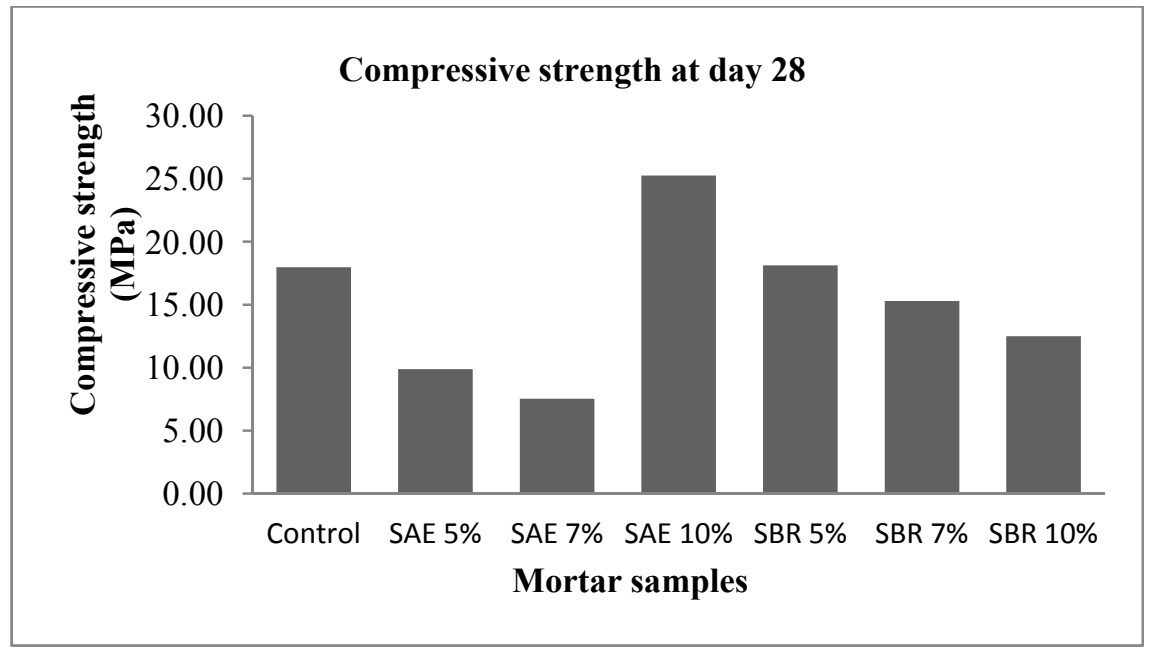

Figure 8: Comparison of 28 days compressive strength between OPC (control), SAEPCCS and SBRPCCS.

\section{Conclusions}

From the PT and SCM investigations performed, it is possible to conclude that SBR and SAE have influenced the efflorescence formation on mortar surfaces to a significant extent. The influence was based on both chemical reactivity and interaction between polymer and cement and on the movement of the polymer particles within the hydrating mortar as its hydration progressed to form pore blocking effects in the microstructures of mortar. This behavior was reflected in the XRD patterns, SEM images and the stronger PCCS results for CS in comparison to conventional mortar. SAEPCC has reduced the efflorescence significantly. It was further validated that the optimum level of SAE polymer addition to mortar was $10 \%$ by weight. Future investigations on the extent of reactivity of other reactive polymer e.g. PAE (Polyacrylic Esters) with $\mathrm{Ca}(\mathrm{OH})_{2}$ using other characterization method are needed to solve efflorescence phenomenon and indirectly improve concrete durability and sustainability.

\section{Acknowledgement}

The authors wish to acknowledge the University Malaysia Sarawak for supporting this work under the FRGS/03(04)/772/2010(53) grant.

\section{References}

[1] Ohama, Y., Recent Progress in Concrete-Polymer Composites. Advance Cement Based Materials, (5), pp. 31-40, 1997. 
[2] Ohama, Y., Polymer-based Admixtures. Cement and Concrete Composites, (20), pp. 189-212, 1998.

[3] Kardon, J.B., Polymer-Modified Concrete: Review. Journal of Materials in Civil Engineering, pp. 85-92, 1997.

[4] Soufiane Benosman, A., Mouli, M., Taibi, H., Belbachir, M., Senhadji, Y., Behlouli, I. \& D, Houivet, D., Mineralogical Study of Polymer-Mortar Composites with PET Polymer by Means of Spectroscopic Analyses. Material Sciences and Applications, (3), pp. 139-150, 2012.

[5] Gomes, C.E.M. \& Ferreira, O.P., Analysis of Microstructural Properties of VA/VEAVA Copolymer Modified Cement Pastes. Polimeros: Ciencia e Tecnologia, (5), pp. 193-198, 2005.

[6] Kresse, P., Efflorescence-Mechanism of Occurrence and Possibilities of Prevention. Betonwerk+Fertigteil-Technik, (53), pp. 160-168, 1987.

[7] Kresse, P., Efflorescence and its prevention. Betonwerk+FertigteilTechnik, (57), pp. 84-88, 1991.

[8] Higgins, D.D., Appearance Matters, No. 4.: Cement and Concrete Association, 1982.

[9] Neville, A., Efflorescence-surface blemish of internal problem? Part 2: Situation in practice. Concrete International, (10), 2002.

[10] Neville, A., Efflorescence-surface blemish of internal problem? Part 1: The knowledge. Concrete International, (24), 2002.

[11] Bensted, J., Efflorescence-prevention is better than cure. Concrete, (24), pp. 40-41, 2000.

[12] Kresse, P., Coloured concrete and its enemy: efflorescence. Chemistry and Industry, pp. 93-95, 1989.

[13] Dow, C. \& Glassier F.P., Calcium carbonate efflorescence on Portland cement and building materials. Cement and Concrete Research, (33), pp. 147-154, 2003. 